\title{
Sciendo
}

DOI: $10.1515 /$ sspjce-2019-0010

\section{Study on utilization of zeolite in concrete precast industry}

\author{
Róbert Figmig, Marek Kováč \\ Technical University of Košice, Slovakia \\ Civil Engineering Faculty, Institute of Environmental Engineering \\ e-mail: rober.figmig@tuke.sk, marek.kovac@tuke.sk
}

\begin{abstract}
Article contains experiment investigating influence of partial cement replacement by zeolite on consistency of fresh concrete, early compressive strength development and temperature development in early stages of curing. Four concrete mixture compositions were tested - containing zeolite in $0 \%, 5 \%, 10 \%$ and $15 \%$ of binder weight. Consistency was tested by flow table test in 5 minutes and 30 minutes after mixing of fresh concrete. Compressive strength and temperature gain were tested after 12, 16, 20 and 24 hours of curing. Results showed significant influence of zeolite on consistency of fresh concrete while compressive strength results were still in the acceptable range.
\end{abstract}

Key words: zeolite, precast concrete, early strength development, flow table test

\section{Introduction}

Trends in environmental protection in every production, transportation and other industry fields lead to minimize the carbon footprint achieving by $\mathrm{CO}_{2}$ emissions reduction to the lowest values. In the concrete production, cement from portland clinker, as its main component, is considered to be the most demanding from the energy consumption point of view and subsequently from the environmental pollution contribution point of view $[1,2,3]$. With the aim to reduce the content of pure clinker in the cement, some mineral additives with pozzolanic (like fly ash, metakaolin, zeolite, silica fume) or latent hydraulic (like ground granulated blast furnace slag GGBS) properties are added directly to the cement as supplement or during concrete production as additive $[4,5,6,7,8,9]$. Considering the complexity of concrete designing issue as a result of technical, economic and environmental requirements, these materials should undergo also detailed assessment before their incorporation into the concrete. Such assessment should take into the consideration parameters like origin (natural or waste, transportation distance), price compared to portland cement, allowed supplement according to technical standard or influence on rheology as well as hardened concrete properties.

It is general known, that commonly used mineral additives used in concrete production either pozzolanic or latent hydraulic are effective in later age of cement hydration. They react with 
free $\mathrm{Ca}(\mathrm{OH})_{2}$ to form $\mathrm{C}-\mathrm{S}-\mathrm{H}$ crystals and that make the concrete matrix denser and more durable [10]. Another fact is, that specific surface, that are influenced by structure and texture of such additive's grains, is often much higher than in the case of Portland cement, what caused higher water consumption for achieving the same consistency of fresh concrete (with same plasticizer/cement ratio) [11]. Regarding the precast concrete, rapid strength development, but also surfaces without aesthetical defects are unconditionally required [12,13,14]. These properties are most often achieved by low water content in the batch together with optimized dosage of superplasticizer to obtain fresh concrete with required viscosity and consistency in time. Another option is using hardening accelerator; however, this solution makes price of $1 \mathrm{~m}^{3}$ of concrete much more expensive and is not economic effective. Noted requirements are obviously in contrast to above stated properties of mineral additives.

In the experiment described in this paper, we were focuses on utilization of zeolite as mineral additive to precast concrete and in the case of meeting demanding requirement, on the evaluation of optimal replacement of cement. The zeolite was chosen as representative of pozzolanic cement supplement material due to its availability and one of the richest sources around the world located in East Slovakia. Despite the fact that zeolite is natural raw material and primarily used in pharmacy, agriculture or wastewater treatment industry $[15,16,17,18,19,20,21]$, there is a feasible potential for its use into the cement composites due to its pozzolanic property $[22,23,24,25,26,27]$ considering currently limited sources, usable and price of common additives as fly ash, GGBS or silica fume in Slovakia region.

\section{Materials and methods}

In this chapter, materials properties and testing methods used in this experiment will be given and described.

\subsection{Materials}

In the experiment, natural fine and coarse aggregate were used. In terms of increasing of visual surface quality of concrete products in precast industry, $0 / 2$ fraction of aggregate with rounded grains is often used in concrete mix design, so it is also the case of this experiment. Gap graded aggregate composition was chosen in the mix designs. The 4/8 fraction of aggregate was removed completely. Fine sand 0/2 originates from Nieznanowice (PL) locality, 0/4 and 8/16 fractions originate from Geča locality (SK). Gradation of aggregate mixture is given in the Fig. 1. Designed aggregate gradation was assessed by boundaries given in [28].

Cement CEM II/A-S 42.5 R from Považská cementáreň, a.s. Ladce (SK) plant and zeolite ZeoBau 50 - Klinoptilolit from Zeocem, a.s. Bystré (SK) were used in the experiment as cementitious materials. 
Polycarboxylate-ether based (superplasticizer SF40 with $34 \mathrm{wt} \%$ of solid content from MAPEI company was used in the experiment as a high-water reduction admixture (HWRA).

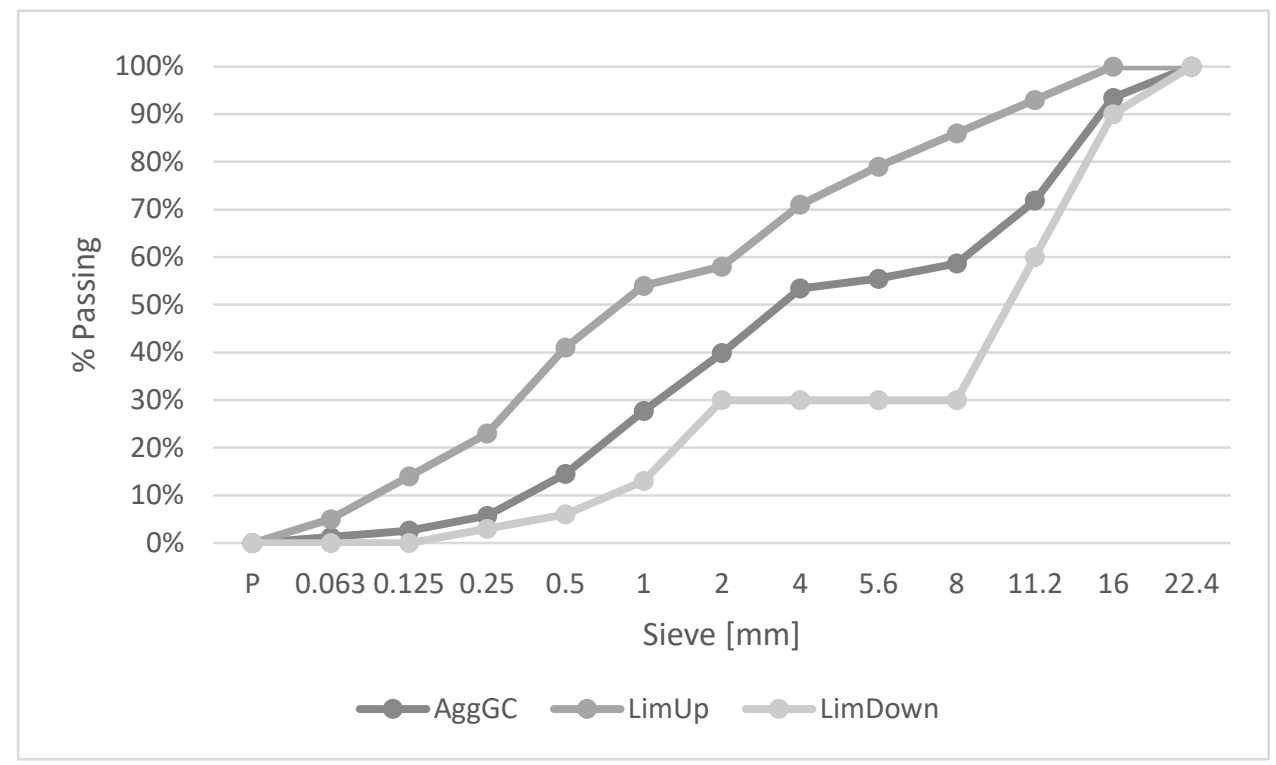

Figure 1: Gradation of aggregate mixture used in mixture designs

Table 1: Chemical composition of binder materials used in the experiment - oxidic form

\begin{tabular}{|l|l|l|l|l|l|l|l|l|r|}
\hline Material & $\mathrm{SiO}_{2}$ & $\mathrm{Al}_{2} \mathrm{O}_{3}$ & $\mathrm{CaO}$ & $\mathrm{K}_{2} \mathrm{O}$ & $\mathrm{Fe}_{2} \mathrm{O}_{3}$ & $\mathrm{MgO}$ & $\mathrm{SO}_{3}$ & $\mathrm{TiO}_{2}$ & $\mathrm{LoI}$ \\
\hline CEM II/A-S 42.5 R & 18.6 & 3.7 & 62.1 & 0.9 & 2.8 & 2.1 & 4.4 & 0.3 & na \\
\hline ZeoBau 50 & 58.7 & 9.0 & 2.8 & 2.6 & 1.4 & 0.7 & 0.1 & 0.2 & 5.1 \\
\hline
\end{tabular}

\subsection{Methods}

Purpose of the experiment is to observe possible usage of zeolite as a supplementary cement material in the concrete precast industry where high early compressive strengths and workability of concrete are essential. Secondary, quality and change of hardened concrete surfaces with changing of zeolite content was observed. Four concrete mixture designs (Table 2) were prepared with ZeoBau 50 content $0 \%, 5 \%, 10 \%$ and $15 \%$ of binder dosage. The temperature of each fresh concrete batch was the same with value $23.8^{\circ} \mathrm{C}$, while $50 \%$ of environment humidity and $22.0^{\circ} \mathrm{C}$ of ambient temperature.

Consistency of fresh concrete was tested by flow table test in 5 min. and $30 \mathrm{~min}$. after mixing. 30 minutes workability time is considered as sufficient in the concrete precast industry. ZeoBau 50 is expected to affect the workability in negative way so all four mix designs are kept with the same amount of mixing water and the same dosage of water reducing admixture to observe and quantify that behavior. 
Table 2: Mix design used in the experiment

\begin{tabular}{|c|c|c|c|c|c|}
\hline Mix design & & ZB-00 & ZB-05 & ZB-10 & ZB-15 \\
\hline $\begin{array}{c}\text { CEM II/A-S } \\
42.5 \mathrm{R}\end{array}$ & {$[\mathrm{kg}]$} & $405(100 \%)$ & $385(95 \%)$ & $365(90 \%)$ & $345(85 \%)$ \\
\hline ZeoBau 50 & {$[\mathrm{~kg}]$} & $0(0 \%)$ & $20(5 \%)$ & $40(10 \%)$ & $60(15 \%)$ \\
\hline $0 / 2$ & \multirow{3}{*}{$\begin{array}{l}{[\%] \text { of total }} \\
\text { aggregate }\end{array}$} & 5 & 5 & 5 & 5 \\
\hline $0 / 4$ & & 50 & 50 & 50 & 50 \\
\hline $8 / 16$ & & 45 & 45 & 45 & 45 \\
\hline HWRA & $\begin{array}{c}{[\%] \text { of }} \\
\text { cementitious }\end{array}$ & 0.75 & 0.75 & 0.75 & 0.75 \\
\hline $\mathrm{w} / \mathrm{b}$ & {$[-]$} & 0.40 & 0.40 & 0.40 & 0.40 \\
\hline
\end{tabular}

Because of lower density of ZeoBau 50 compared to used cement, it is also expected the unit weight (in fresh and hardened state) of concrete to be lower with ZeoBau 50 compared to reference mixture without it.

For compressive strength testing, cube samples of $150 \mathrm{~mm}$ side were made. As it is important for precast concrete industry, early strength of concrete was tested in the experiment. Concrete made of four different mix designs containing ZeoBau 50 was tested on compressive strength after $12 \mathrm{~h}, 16 \mathrm{~h}, 20 \mathrm{~h}$ and $24 \mathrm{~h}$ of curing. Along with the compressive strength, the temperature of concrete samples was measured in respective times to get information on ongoing exothermic chemical reactions thus rate of compressive strength development could be predicted. Specimens were kept in the forms until strength testing. Standard plastic molds with insulating caps were used. The ambient temperature during curing varied from 19.5 up to $22.5{ }^{\circ} \mathrm{C}$.

\section{Results and discussion}

\subsection{Consistency}

Results of consistency of fresh concretes are given in Fig. 2 and in comparative Fig. 3. As expected, the consistency of fresh concrete was the stiffer the higher percentage of ZeoBau 50 was introduced into the concrete mixture. It could be explained by higher water demand of zeolite and its characteristic mesh which traps molecules of water. Mixture ZB-00 made of $100 \%$ cement binder achieved in flow table test $620 \mathrm{~mm}$ at the beginning and $625 \mathrm{~mm}$ after 30 minutes. Considering initial fresh concrete temperature, this result could be evaluated as greatly satisfactory. The reason for that obviously resides in proper composition and function of cement-water-plasticizer system. Mixture ZB-05 made of 5\% ZeoBau 50 as cement replacement achieved $520 \mathrm{~mm}$ and $500 \mathrm{~mm}$ in flow table test in respective times. Even with small portion of zeolite incorporating, the consistency change is significant but still usable in terms of concrete precast conditions. Mixture ZB-10 made of 10\% ZeoBau 50 as cement replacement achieved $405 \mathrm{~mm}$ and $360 \mathrm{~mm}$ in flow table test in respective times. It can be seen here not only the stiffer consistency at the beginning but also a bigger consistency loss in time. It can be attributed to lower content of "free" water in the fresh concrete but also to sorption abilities of zeolite minerals which could consume the water reducer particles more rapidly. Mixture ZB-15 made of 15\% ZeoBau 50 as cement replacement achieved only $330 \mathrm{~mm}$ and 
$280 \mathrm{~mm}$ in flow table test in respective times. Mixture ZB-15 flow table test values dropped under $340 \mathrm{~mm}$ which is a recommended boundary for using method of flow table test for concrete consistency determination. Experiment proved and quantified the consistency loss due to incorporating zeolite based supplementary cementitious material. Differences are quite significant even at small portions used.

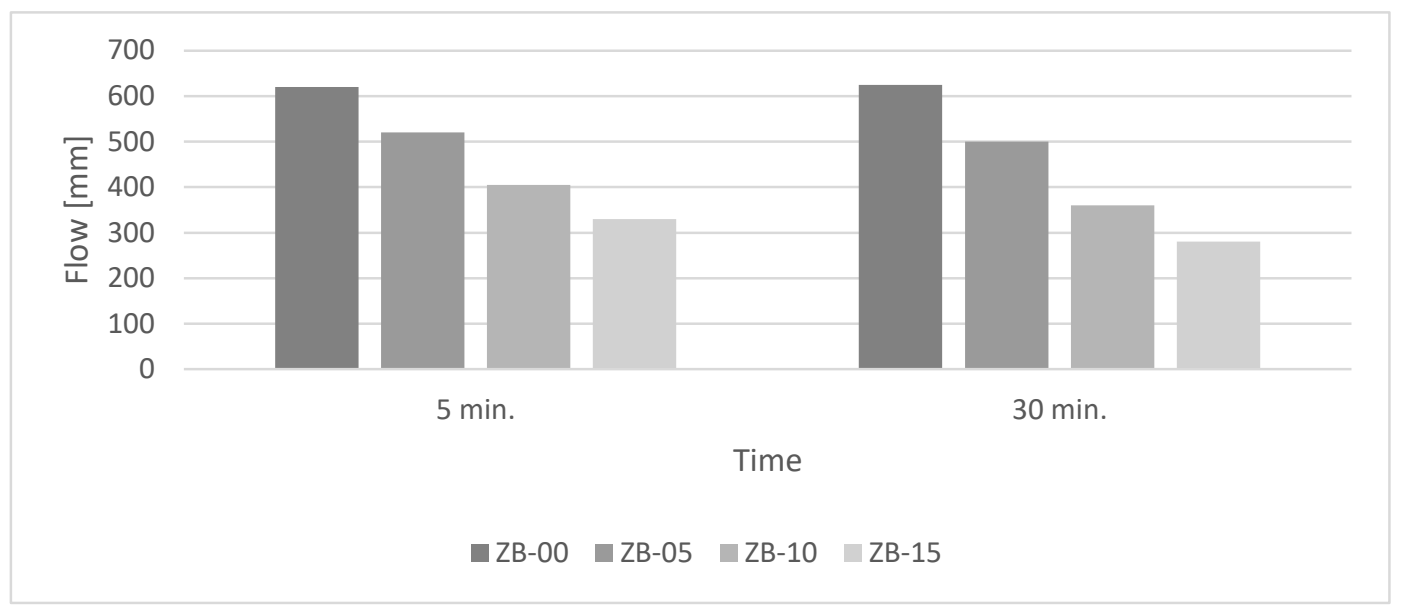

Figure 2: Consistency of concrete with zeolite content
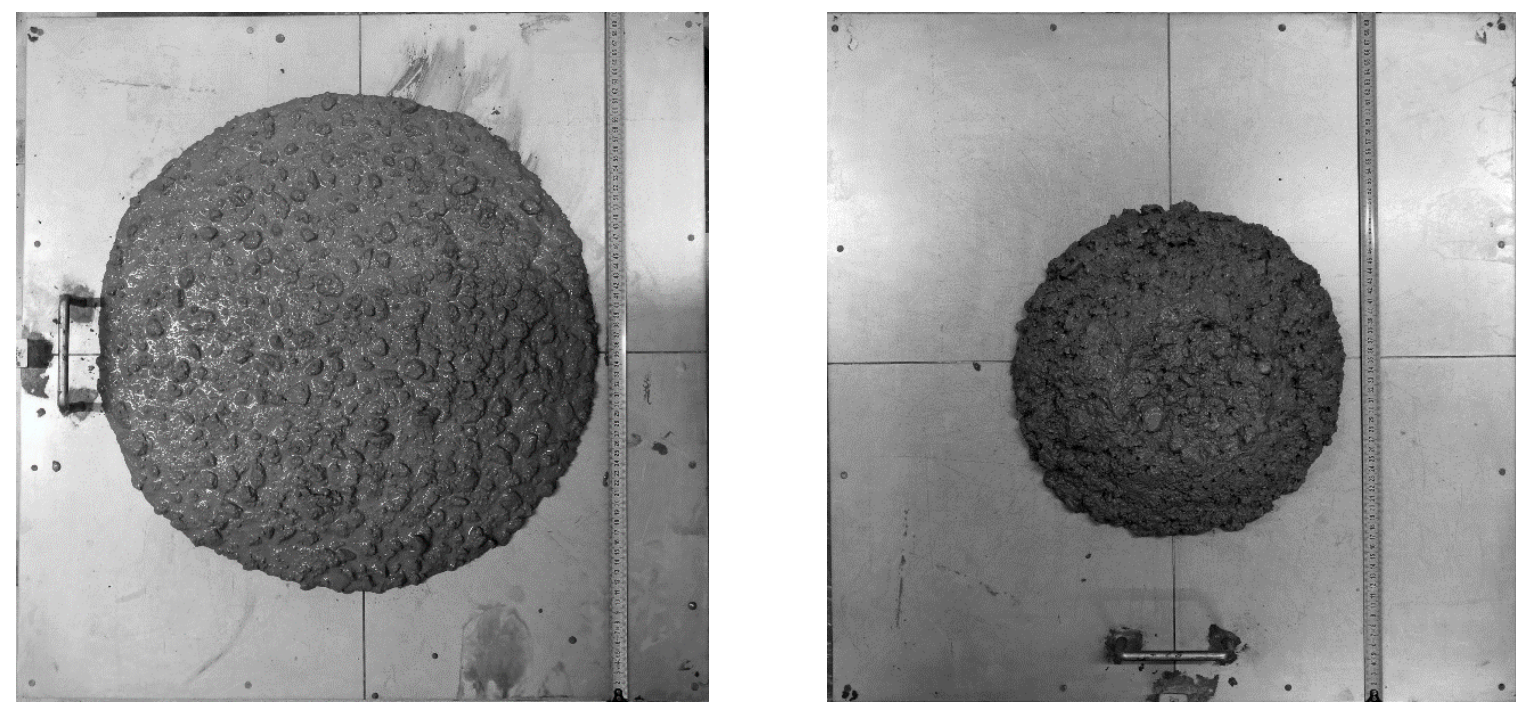

Figure 3: Consistency of concrete after 5 minutes - ZB-05 (left) and ZB-15 (right)

\subsection{Compressive strength}

Results of compressive strength of tested concrete mixtures are given in

Figure 4. After 12 hours of curing the highest the portion of zeolite the higher the compressive strength. It ranges from 6.1 MPa (ZB-00) to 8.0 MPa (ZB-15). Fact that zeolite consumes 
significant amount of water could actually resulted in lower w/b than was calculated and assumed in mixture design. This behavior could result in faster development of compressive strength of samples containing zeolite. After 16, 20 and 24 hours of curing, the trend is opposite and the higher the content of zeolite the lower the compressive strength. This behavior could be attributed to ongoing pozzolanic activity which is known to be significant slower than standard hydration reactions of Portland cement. The difference between the highest and the lowest strength value after 16 hours of curing is $4.0 \mathrm{MPa}$, after 20 hours of curing it is $6.0 \mathrm{MPa}$ and after 24 hours of curing it is $8.7 \mathrm{MPa}$.

Temperature development (Fig. 6) of concrete samples were recorded using IR thermometer at respective curing time right before demolding of samples. The temperature development shows the exact same behavior as the strength development. The recorded peak of temperature was recorded after 16 hours of curing in maximum of $36.5^{\circ} \mathrm{C}$ for $\mathrm{ZB}-00,35.5^{\circ} \mathrm{C}$ for $\mathrm{ZB}-05,34.8$ for $\mathrm{ZB}-10$ and 33.2 for $\mathrm{ZB}-15$. Again, the lowered w/b ratio caused by presence of zeolite in the mixture could caused faster heat development after 12 hours of curing, but lower dosage of cement is responsible for lower heat development after 16, 20 and 24 hours of curing where even effect of lowered $\mathrm{w} / \mathrm{b}$ ratio was overcome.

Incorporation of zeolite into concrete mixtures also caused slight decrease in unit weight (Fig. 5). The highest unit weight $\left(2400 \mathrm{~kg} / \mathrm{m}^{3}\right)$ was achieved by ZB-00 mixture without using zeolite. Mixtures containing zeolite achieved unit weight in range from $2363 \mathrm{~kg} / \mathrm{m}^{3}$ to $2374 \mathrm{~kg} / \mathrm{m}^{3}$.

In general, $12 \mathrm{MPa}$ is considered (may vary in specific cases) to be sufficient strength to demold and manipulate with precast concrete segment or product. None of tested mixtures achieved that value after 12 hours of curing but all of them achieved it after 16 hours of curing even the ZB-15 with the highest portion of replaced cement.

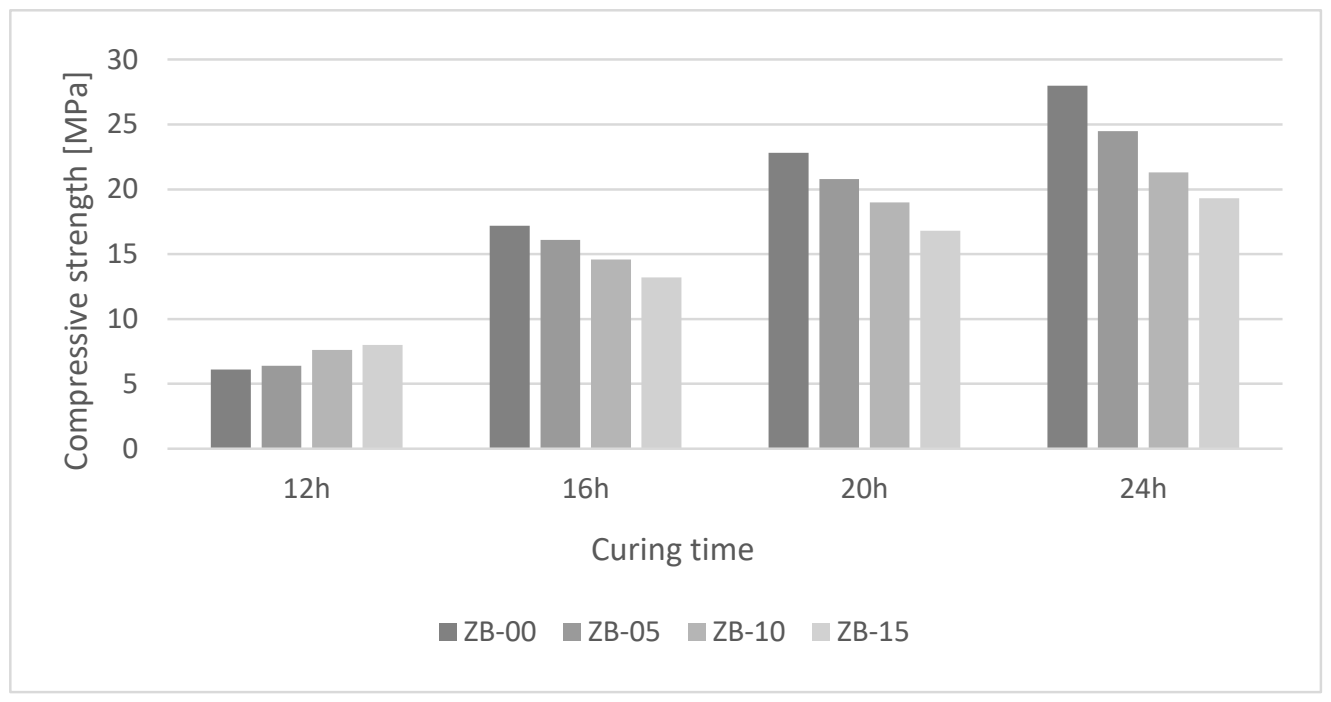

Figure 4: Compressive strength of concrete specimens at respectively curing times 




Figure 5: Unit weight of concrete mixtures made of various content of ZeoBau 50



Figure 6: Temperature of concrete specimens at respectively curing times

In the Fig.7 is presented comparation between hardened concrete surface of samples ZB-00 and ZB-05. The samples with no zeolite evinced only flat cavern unlike the samples with zeolite, where bugholes are presented evidently, what could be associated with increasing viscosity with higher zeolite content. Entrapped air then more difficultly squeezed out at a mold wall surface. 

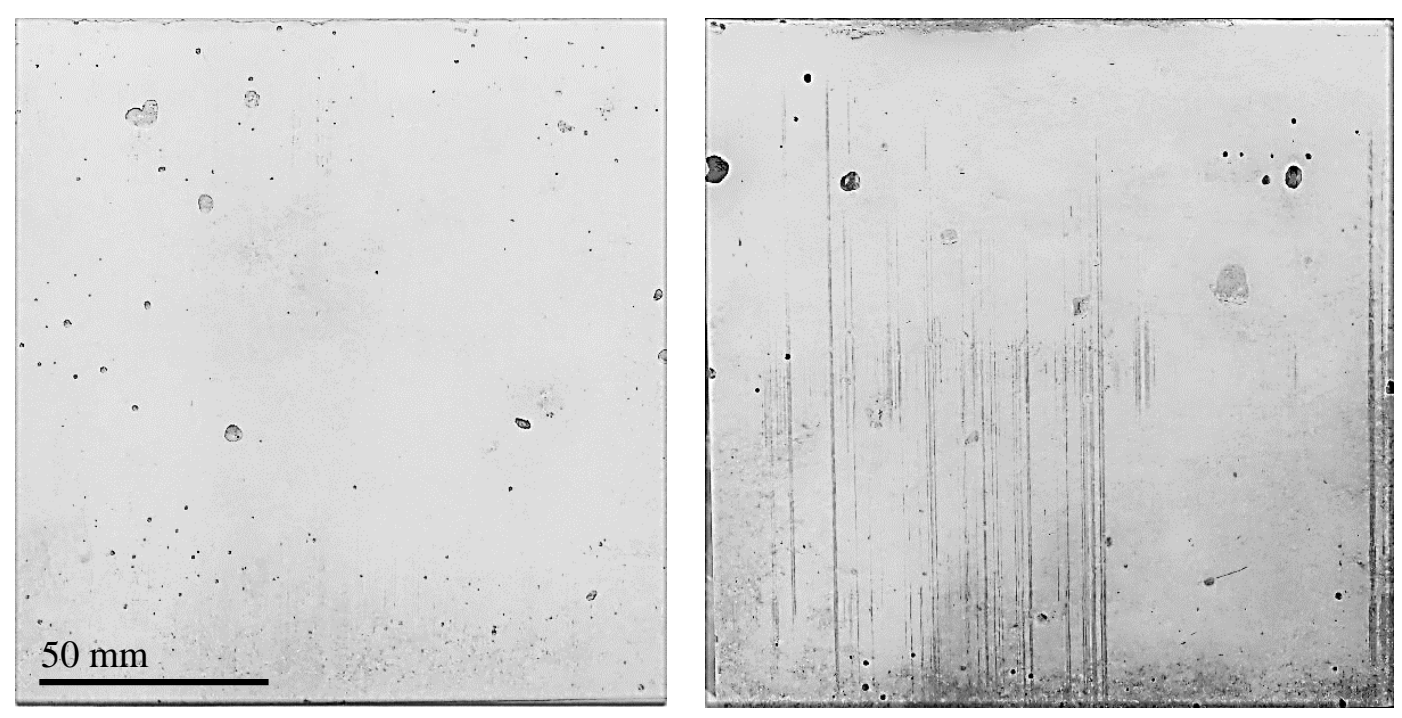

Figure 7: Comparison of hardened concrete surface - ZB-00 (left) and ZB-05 (right)

\section{Conclusion}

Experiment given in the article focused on the possible utilization of zeolite in concrete precast industry. Consistency of fresh concrete, temperature development and early compressive strength development of concrete containing 5\%, 10\% and 15\% of zeolite as cement replacement were investigated. Based on experiment results, following observations could be formulated:

- zeolite significantly affects consistency of fresh concrete in negative way,

- the highest compressive strength and temperature gain after 12 hours of curing were achieved by ZB-15 mixture (the highest portion of zeolite $-15 \%$ ),

- the highest compressive strength and temperature gain in all other curing times $(16,20$ and 24 hours) were achieved by ZB-00 mixture ( $0 \%$ content of zeolite),

- all of tested concrete mixtures achieved $12 \mathrm{MPa}$ of compressive strength after 16 hours of curing, $12 \mathrm{MPa}$ is considered as sufficient strength to manipulate with precast concrete segment (may vary in specific cases).

Experiment suggests possibility of zeolite utilization in concrete precast industry, but few issues have to be overcome. Mainly consistency and workability of fresh concrete containing zeolite need to be adjusted by combination of added water and/or plasticizer. The effect of this adjustment on compressive strength will be the subject of future research.

\section{Acknowledgements}

This paper has been prepared with a support of the Scientific Grant Agency of the Ministry of Education, Science, Research and Sport of the Slovak Republic and the Slovak Academy of Sciences (VEGA Grant No. 1/0648/17). 


\section{References}

[1] Machado I. L et al. (2018). Improvement of the Environmental Energy Sustainability in the Production of Cement Portland with Addition of Thermally Activated Clays. In Martirena F., Favier A., Scrivener K. (eds) Calcined Clays for Sustainable Concrete. RILEM Bookseries, vol 16. Springer, Dordrecht.

[2] Singh, G. B. \& Subramaniam, K. V. (2019). Production and characterization of low-energy Portland composite cement from post-industrial waste. Journal of Cleaner Production. 239, 118024.

[3] Oliveira, F. C. et al. (2019). Portland cement clinker production using concentrated solar energyA proof-of-concept approach. Solar Energy. 183, 677-688.

[4] Kupwade-Patil, K. et al. (2018). Impact of Embodied Energy on materials/buildings with partial replacement of ordinary Portland Cement (OPC) by natural Pozzolanic Volcanic Ash. Journal of cleaner production. 177, 547-554.

[5] Carvalho, S. Z. et al. (2018). Reducing environmental impacts: The use of basic oxygen furnace slag in portland cement. Journal of cleaner production. 172, 385-390.

[6] Ustabaş, İ. \& Kaya, A. (2018). Comparing the pozzolanic activity properties of obsidian to those of fly ash and blast furnace slag. Construction and Building Materials. 164, 297-307.

[7] Cavalcante, D. G. et al. (2018). Influence of the levels of replacement of portland cement by metakaolin and silica extracted from rice husk ash in the physical and mechanical characteristics of cement pastes. Cement and Concrete Composites. 94, 296-306.

[8] Liu, Y. et al. (2018). Alkali-treated incineration bottom ash as supplementary cementitious materials. Construction and Building Materials. 179, 371-378.

[9] Yakubu, Y. et al. (2018). Potential application of pre-treated municipal solid waste incineration fly ash as cement supplement. Environmental Science and Pollution Research. 25 (16), $16167-$ 16176.

[10] Tokyay, M. (2016). Cement and concrete mineral admixtures. Boca Raton: CRC Press.

[11] Khan, S. U. et al. (2014). Effects of different mineral admixtures on the properties of fresh concrete. The Scientific World Journal. 2014, 1-11.

[12] Elliott, K. S. (2016). Precast concrete structures. Boca Raton: CRC Press.

[13] Bachmann, H. \& Steinle, A. (2011). Precast concrete structures. Berlin: Ernst \& Sohn.

[14] Levitt, M. (1982). Precast concrete: materials, manufacture, properties and usage. Boca Racon: CRC Press.

[15] Auerbach, S. M., Carrado, K. A. \& Dutta, P. K. (2003). Handbook of zeolite science and technology. Boca Raton: CRC press.

[16] Moshoeshoe, M., Nadiye-Tabbiruka, M.S. \& Obuseng, V. (2017). A review of the chemistry, structure, properties and applications of zeolites. American Journal of Materials Science. 7 (5), 196-221.

[17] Muir, B. \& Bajda, T. (2016). Organically modified zeolites in petroleum compounds spill cleanup-Production, efficiency, utilization. Fuel processing technology, 149, 153-162.

[18] Karakurt, C., Kurama, H. \& Topcu, I. B. (2010). Utilization of natural zeolite in aerated concrete production. Cement and Concrete Composites. 32 (1), 1-8. 
[19] Koshy, N. \& Singh, D. N. (2016). Fly ash zeolites for water treatment applications. Journal of Environmental Chemical Engineering. 4 (2), 1460-1472.

[20] Rashed, M. N., \& Palanisamy, P. N. (2018). Introductory Chapter: Adsorption and Ion Exchange Properties of Zeolites for Treatment of Polluted Water. Zeolites and Their Applications, 1.

[21] Jakkula, V. S. \& Wani, S. P. (2018). Zeolites: Potential soil amendments for improving nutrient and water use efficiency and agriculture productivity. Scientific Reviews \& Chemical Communications. 8 (1), 1-15.

[22] Lv, Y., Ye, G. \& De Schutter, G. (2019). Investigation on the potential utilization of zeolite as an internal curing agent for autogenous shrinkage mitigation and the effect of modification. Construction and Building Materials. 198, 669-676.

[23] Hajforoush, M., Madandoust, R. \& Kazemi, M. (2019). Effects of simultaneous utilization of natural zeolite and magnetic water on engineering properties of self-compacting concrete. Asian Journal of Civil Engineering. 20 (2), 289-300.

[24] Tran, Y. T., et al. (2018). Natural zeolite and its application in concrete composite production. Composites Part B: Engineering. 165, 354-364.

[25] Zhang, J. et al. (2018) Effective solution for low shrinkage and low permeability of normal strength concrete using calcined zeolite particles. Construction and Building Materials. 160, $57-$ 65 .

[26] Nagrockiene, D. \& Girskas, G. (2016). Research into the properties of concrete modified with natural zeolite addition. Construction and Building Materials. 113, 964-969.

[27] Ahmadi, B. \& Shekarchi, M. (2010). Use of natural zeolite as a supplementary cementitious material. Cement and Concrete Composites. 32, 134-141.

[28] SUTN. (2015). STN EN 206/NA. Concrete. Specification, performance, production and conformity - National Anexx. Slovakia. 